\title{
Assistolia Durante Ecocardiograma de Estresse com Dobutamina
}

\author{
Rita Pinton, Hermínio Haggi Fo, W almor Lemke, O limpio R. França $N$ eto \\ Curitiba, PR
}

Caso de assistolia, durante a realização de ecocardiografia de estresse com dobutamina, em mulher de 59 anos, com queixa de dor precordial. A complicação não foi associada com isquemia miocárdica e deve ter sido causada pela estimulação dos receptores cárdio-inibidores cardíacos à ação da dobutamina. A assistolia cardíaca foi revertida após administração de atropina, sem seqüelas.

\section{Cardiac Asystole during Dobutamine Stress Echocardiography}

We report a case of cardiac asystole during dobutamine stress echocardiography in a 59 year-old woman presenting with chest pain and a positive treadmill test for ischemia. Cardiac asystole was not associated with myocardial ischaemia and was probably related to a powerful cardioinhibitory reflex caused by dobutamine stimulation.

Arq Bras Cardiol, volume 70 (n 6), 435-436, 1998

Extra-sistolia ventricular e atrial são as complicações mais freqüentemente associadas à ecocardiografia de estresse com dobutamina. A arritmia ventricular pode ser atribuída à atividade predominante da dobutamina de estimulação do receptor B1 adrenérgico. Por outro lado, a infusão de dose alta de dobutamina, pode resultar em ação paradoxal de inibição simpática e aumento da atividade parassimpática, com redução da freqüência cardíaca $(\mathrm{FC})$, geralmente acompanhada de náuseas e hipotensão. Esta resposta cárdio-inibitória pode ser manifestação do reflexo de Bezold-Jarisch, cuja expressão extrema é assistolia.

A assistolia parece ser uma complicação extremamente rara da ecocardiografia de estresse com dobutamina, não tendo ocorrido em mais de 5.000 testes de alguns estudos ${ }^{1-3}$, e tendo sido relatada em apenas um caso recentemente publicado ${ }^{4}$.

\section{Relato do Caso}

Mulher de 59 anos de idade, apresentou um episódio de dor precordial atípica. História pregressa de aproximadamente seis episódios de síncope, iniciados na infância e desencadeados por apreensão. O eletrocardiograma (ECG) demonstrou alteração da repolarização ventricular na face inferior. O teste de esforço foi positivo para isquemia com

Santa Casa de Misericórdia de Curitiba

Correspondência: Rita Pinton - Rua Siqueira Peixoto, 555 - 80240-120 - Curitiba, PR

Recebido para publicação em 12/2/98

Aceito em 7/4/98 infradesnível retificado de ST de 2,0mm em CM5 e aVF. Como a paciente não apresentasse outro fator de risco para doença coronária, além da menopausa, foi submetida a ecocardiografia de estresse para confirmação diagnóstica.

O ecocardiograma mostrou ventrículo esquerdo (VE) com dimensões, função sistólica global e regional normais. Não se evidenciaram alterações morfológicas ou funcionais das estruturas cardíacas. O ecocardiograma de estresse foi obtido com protocolo de infusão progressiva de $5,10,20,30$ e $40 \mu \mathrm{g} / \mathrm{kg} / \mathrm{min}$ de dobutamina a cada $3 \mathrm{~min}$. Em condição basal a pressão arterial (PA) era de 110/70 $\mathrm{mmHg}$ e a FC de 70bpm.

A paciente não fazia uso de nenhuma medicação e era cooperativa e bastante calma. A resposta à dobutamina foi normal até dose máxima infundida de $30 \mu \mathrm{g} / \mathrm{kg} / \mathrm{min}$. Houve resposta normal hipercinética do VE e aumento da pressão sistólica para $160 \mathrm{mmHg}$ no pico do estresse, a pressão diastólica manteve-se estável. A FC atingiu 139bpm, istoé, 86\% da máxima prevista para a idade. No fim desse estágio, a paciente desenvolveu taquicardia ventricular não sustentada (5bpm), com súbita diminuição da freqüência para $50 \mathrm{bpm}$ em ritmo sinusal. Medicada com $1 \mathrm{mg}$ de atropina endovenosa, a arritmia evoluiu rapidamente para assistolia cardíaca, causando perda de consciência. Foi iniciada massagem cardíaca. Após 8,40s de assistolia, ritmo sinusal foi restaurado. A paciente recuperou completamente a consciência, sem seqüelas neurológicas. O ecocardiograma eECG não apresentaram evidências de isquemia. No dia seguinte foi obtida arteriografia coronária que não demonstrou lesões obstrutivas. 


\section{Discussão}

A ecocardiografia de estresse com dobutamina é técnica bem difundida na investigação da doença coronária. A dobutamina é uma amina simpaticomomética que possui propriedades adrenérgicas alfa-1, beta-1 e beta- 2 . Com as doses habitualmente empregadas, os receptores beta- 1 são primariamente estimulados, provocando resposta inotrópica maior do que cronotrópica. Com doses mais elevadas, observa-se estímulo dos receptores beta-1 e beta-2, com resposta cronotrópica e inotrópica equivalentes.

A indução de isquemia durante infusão de dobutamina é dependente da FC. No entanto, em alguns pacientes, é observada resposta paradoxal bradicárdica com doses elevadas de dobutamina. Geralmente ocorre a tríade de bradicardia, hipotensão e naúsea. Temos observado que atropina é efetiva para aumentar a FC e diminuir esses sintomas. O mecanismo do reflexo cárdio-inibidor parece se originar nos receptores sensoriais cardíacos, com vias vagais aferentes não mielinizadas e recebe o nome de reflexo de Bezold-Jarisch ${ }^{5}$. O VE, particularmente a parede inferior, é a principal localização desses receptores. Eles são influenciados por estímulo mecânico ou químico, e sua estimulação resulta em aumento da atividade parassimpática e em inibição da atividade simpática.

Dada a localização preferencial dos receptores sensoriais, o estímulo pode ocorrer no infarto do miocárdio inferior. Hopfenspirger e col ${ }^{6}$ relataram desaceleração sinusal em 10 pacientes, durante cintilografia de perfusão com dobutamina. Todos apresentavam sinais cintilográficos de isquemia em parede inferior, porém sem confirmação pela angiografia coronária. Ao contrário, no estudo de Attenhofer e $\mathrm{col}^{7}$, que muito bem caracterizaram desaceleração sinusal durante ecocardiografia de estresse com dobutamina, o reflexo ocorreu em $8 \%$ dos pacientes estudados, todos sem doença coronária.

Em ratos com volume cardíaco diminuído pela oclusão da veia cava, a reação vasodepressora e cárdio-inibitória (bradicardia paradoxal) foi induzida pela infusão de isoproterenol e dobutamina ${ }^{8}$. A indução da resposta vasodepressora no homem pode ocorrer com a administração de isoproterenol durante teste de inclinação ( $t i l t$ teste) em pes- soas com propensão para síncope. A reação vasodepressora e cárdio-inibitória pode ocorrer em qualquer situação em que exista redução do volume intracardíaco combinada com estimulação beta-1 adrenérgica. Ambas situações podem ser causadas pela dobutamina.

$\mathrm{O}$ aparecimento de assistolia em nossa paciente, com história de quadro sincopal, sugere síncope neurogênica, isto é, mediada pelo sistema nervoso autônomo. Essa situação originou aumento da sensibilidade à ação inotrópica positiva da dobutamina, que, estimulando os mecanoreceptores da parede inferior do $\mathrm{VE}$, desencadeou intensa reação vagal (reflexo de Bezold-Jarisch), evoluindo para assistolia. Somado aos efeitos da infusão de dobutamina, o grau leve de hipovolemia pelo jejum de $4 \mathrm{~h}$, antecedendo a realização do exame, resultou em diminuição do volume intracardíaco, o que facilitou a ocorrência da resposta vasodepressora e cárdio-inibitória.

Em nosso caso, não se pôde atribuir à isquemia em região inferior o desencadeamento dessa resposta. A hipercinesia difusa do VE resultante da infusão de dobutamina e a angiografia coronária normal excluem a possibilidade de doença coronária.

O único caso de assistolia descrito na literatura, como complicação da ecocardiografia de estresse, foi atribuído à estimulação dos baroreceptores dos grandes vasos, por aumento da PA sistólica ${ }^{4}$. Em nossa paciente, a assistolia não foi precedida por aumento marcado da PA.

Assim, concluímos que a ecocardiografia de estresse com dobutamina pode originar assistolia e síncope. O fenômeno é provavelmente causado pelo reflexo de BezoldJarisch. Embora esse reflexo possa estar relacionado à doença coronária, pode ocorrer na ausência de isquemia miocárdia ou anormalidades coronárias na cineangiografia.

O relato desse caso sugere que o teste deve ser conduzido com cautela, em pacientes com história de síncope e que atropina deve estar disponível, para contrabalançar a ação vagal induzida pela dobutamina.

\section{Agradecimentos}

Ao Dr José Carlos Moura Jorge, pela orientação na análise da arritmia.

\section{Referências}

1. Secknus MA, Marwick TH - Evolution of dobutamine echocardiography protocols and indications: safety and side effects in 3,011 studies over 5 years. J Am Coll Cardiol 1997; 29: 1234-40.

2. Mertes H, SawadaSG, Ryan Tetal-Symptoms, adverse effects, and complications associated with dobutamine stress echocardiography. Experience in 1118 patients. Circulation 1993; 88: 15-9.

3. Pinton R, Lemke W, Garcia L - Sintomas, complicações e alterações hemodinâmicas associadas a ecocardiografia de estresse com dobutamina. Arq Bras Cardiol 1997; 69: 161-4.

4. Lanzarini L, Previtali D - Syncope caused by cardiac asystole during dobutamine stress echocardiography. Heart 1996; 75: 320-1.
5. Mark AL-The Bezold-Jarisch reflex revisited: clinical implications of inhibitory reflexes originating in the heart. J Am Coll Cardiol 1983; 1: 90-102.

6. Hopfenspirger MR, Miller TD, Chistian TF, Gibbons J - Sinus node deceleration during dobutamine perfusion scintigraphy as a marker of inferior ischemia. Am J Cardiol 1994; 74: 817-9.

7. Attenhofer CH, Pellikka PA, McCully RB, Roger V, Seward JB - Paradoxal sinus deceleration during dobutamine stress echocardiography: description and angiographic correlation. J Am Coll Cardiol 1997; 29: 994-9.

8. Waxman MB, Asta JA, Cameron DA- Vasodepressor reaction induced by inferior vena cava occlusion and isoproterenol in the rat: role of beta- 1 and beta- 2 adrenergic receptors. Circulation. 1994; 89: 2401-11. 